\title{
Medicine's Great Journey
}

\author{
Das CR \\ Professor and HOD \\ Department of Anaesthesiology and Critical Care \\ Nobel Medical College \& Teaching Hospital, \\ Biratnagar-05, Morang, Nepal
}

Self Revelation- "To write an article of any sort, is to some extent, to reveal ourselves. Hence, even a medical article is, in a sense, something of an autobiography".(John Dicosta) In this new millennium a bewildering array of chemicals, gases and other electronics are used to manufacture various kinds of drugs, equipment and devices to fight against various diseases to take care of health of human beings. Here in, lies the importance and utility of medical sciences which was stressed long back by outstanding Jewish prophet and physician of all times. "A healthy soul can exist only in a healthy body and that medicine, therefore, has an important part to play in ethics and religion".

Today the fundamental aims of all branches of medical sciences is to relieve pain and sufferings from various diseases and surgical interferences. But the days were different in the older days. As per WHO's latest report about how civilized a country is shown by the amount of care it takes for its weaker sections i.e. children and women.

Way back in 1591, a young lady named Eupharine Macaly was burnt alive as punishment for seeking pain relief during labour by the order from the king of Scotland James VI. Nobody raised any objection to this inhuman act. Ultimately Francis Bacon (151-1626) was the first one who raised his voice "I esteem it the office of physicians not only to restore health but mitigate pain and dolor." (WHO) Medical science of today is entirely different from what it was yesterday. We all have received a magnificent endowment from our predecessors viz. medicines, drugs, techniques, various other monitoring devices which we use everyday to bring comfort to our patients. These were possible due to the untiring efforts of our predecessors with round knowledge of anatomy, physiology, pharmacology and medicines, so it is very essential to remember the past if we want to progress further in future. In this regard it is wise to recall the preface of Robert Coles famous book viz. Medical Journey through 100 years. "The past is the ground on which we walk and if we don't know the soil, we are lost and sure to miss the future".
If we look back to the evolution of mankind, there was no cellular life when Earth appeared in this universe as the atmosphere was reducing on containing mostly hydrogen. With the passage of time and by the grace of god the reducing atmosphere was transformed into an oxidizing one containing mostly oxygen (oxidizing atmosphere) as an energy source and cellular life appeared as oxygen was abundant, access able and possessed a high potential. In this way life forms developed utilizing oxygen as the primary biomedical storage type of energy. The history of discovery of oxygen in 1774 by Joseph Priestly, is probably the most dramatic and exciting discovery in modern medicine of all centuries. The energy generation from oxygen keeps the human engine alive.

Modern Medicine took birth from 1500 AD onwards, i.e. the period of Political and medical revolution and today it is as much science as it is an art. AS a matter of fact evolution of medicine is the essence of evolution of man.

In the era of primitive medicine (500 BC to $500 \mathrm{AD}$ ) diseases were considered to be due to wrath of God and there were many supernatural theories of it. As the first man was, probably, the first doctor and the first woman was the first nurse. Ancient system of medicine originated and was practiced in India, China, Egypt, Mesopotamia, Greece and Rome. Probably the Romans established the $1^{\text {st }}$ hospitals with the burrowed medicines from Greeks.

Middle ages (500 A.D to 1500 A.D) was considered the "Dark ages of Medicine". Europe ravaged by small pox, plague, leprosy, tuberculosis. History goes full circle. Medicine, again, became primitive. But during this period only Arabians, Christians and Buddhist medicine evolved. First hospital on record was built in England in 937 AD at York. Monasteries were established by Buddhists where they preserved the ancient knowledge and use to render medical and nursing care to the sick.

In $16^{\text {th }}$ century Andreas Vesalius (1514-1564), $1^{\text {st }}$ dissected human body and John Hunter (1728-1793) taught the science of surgery.

Association of "United company of Barber surgeons", later on known as "Royal college of surgeon" was established in England. $17^{\text {th }}$ and $18^{\text {th }}$ century was still more interesting. William Harvey 
discovered the circulation of blood in 1628, Leewenhock discovered microscope in 1670, E. Jenner prepared vaccination against small pox in 1796. Louis Pasteur (1822-1895) demonstrated bacteria in air in 1860 and introduced the system of sterilization, Robert Koch (1843-1910) demonstrated that Anthrax was caused by bacteria and many more. As a matter of fact this was the golden age of bacteriology. Microbe after microbe was discovered like Gonococcus (1957), Typhoid and Pneumococcus (1980), Tubercle bacilli (1882), Cholera vaccine (1883), Diphtheria (1884). Lastly in $20^{\text {th }}$ century HIV was discovered in 1983. One of the most greatest advancement in last 2 centuries was discovery of chemotherapy against infection which traced through distinct periods viz. Pre-Ehrich era (before 1891), Ehrich year (1854-1915) and period after 1915 discovery of sulfonamides and antibiotic penicillin in 1928 which was used in 1949. Last century was the era of specialization. Etiology of diseases were shifted from germ theory to genetic, environmental, economic and psychological theories. Watson and Creik in 1963 put forward DNA model. Genetic mapping became reality and human genome project started in 2005. Discovery of biological role of nucleic acid and uncovering the genetic code has provided basis for genetic counseling and engineering, pre natal diagnosis of sex and genetic diseases, in vitro fertilization and cloning. Today Medicine has moved from organism to organ, from organ to cell, from cell to its molecular properties.

Toaday medicine has advanced so much that almost every organ of human body is subjected to allographic transplantation.

In ancient as well as modern times, there is a truth in the aphorism that "the easiest pain to bear is someone else's". before the introduction of anaesthesia, most surgeon used to believe that pain and unexplained sudden death were and would always be an inevitable consequences of surgery. In those dark days many patients, while awaiting even for a minor elective procedure often put their estate and personnel affairs in order in the anticipation that their wealth would soon be passed on to the next kin. Interestingly wine was being used both in the eastern and western world to produce anaesthesia.
It is worth mentioning here that in those days king Bhoja of india in $1927 \mathrm{AD}$ underwent a craniotomy under the influence of "Somohini" and recoverd after the surgery by using "Sanjivani". The typical anesthesia produced by chewing Coca leaves was known only to the INCAS of south America before Pizarr's conquest. But modern anesthesia date back to the public demonstration of administration of ether at the surgical Amphitheatrae of the Massachussett's Gm. Hospital in Boston on October $16^{\text {th }} 1846$. William T.G. Morton. In 1853 Alexender wood invented hypodermic and parbez syringe which have made injection of drugs as well as regional anesthesia possible. Another exciting event of $19^{\text {th }}$ century is the demonstration of topical anesthetic property of cocaine by carl kollar in 1884 . There are many more. Every branch of specialty of medicine is progressing very fast because what is ideal today is becoming obsolete. As a matter of fact the medical professionals at the end of this century will find themselves in an environment which will have no resemblance with today. Specially the field of transplant surgery will extend tremendously.

Probably every organ after human body will be subjected to allographic replacement. Micro-surgical advances will make possible transplantation of genetically engineered tissue to cure many diseases. Even some medical illness like schizophrenia, depression or addiction may be treated by surgical transplantation of cultured tissue. Microprocessor advances in the field of exogenous reinnervation of skeletal muscle will require surgical implantation of electrodes in various muscle group. Research is on to find an anaesthetic agent, toxic only to viruses or infectious agents. If it became a reality, question of anaesthetic administration will arise to treat acute fulminating infectious illness. Possibility of a nuclear war, on a limited and subsequent anaesthetic administration to patients suffering from radiation poisoning or burns cannot be ruled out. Tackling problems of AIDS, Alzhiemer's disease, coronary artery disease and cancer has become bigger priorities. "Beat to Beat" or "Breadth to Breadth" monitoring may become new essential safety standard of practice. 